\title{
Effects of purification on the crystallization of lysozyme
}

\author{
Felecia L. Ewing a, Elizabeth L. Forsythe ${ }^{a}$, Mark van der Woerd ${ }^{b}$, \\ Marc L. Pusey ${ }^{c, *}$
}

"Universities Space Research Association, 4950 Corporate Drive, Suite 100, Huntsville, Alabama 35812, USA

'University of Alabama, Birmingham, Alabama 35294, USA

' Biophysics ES76. National Aeronautics and Space Administration, Marshall Space Flight Center. Huntsville, Alabama 35812, USA

Received I February 1995; accepted 2 September 1995

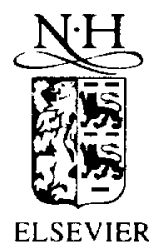




\section{EDITORIAL BOARD}

M. SCHIEBER (Principal Editor) Dept. Materials Science.

Schosl Appl. Sci. * Technol

Hetrew University, Jerusalem 919/4. Israel

Telefiax: + 472-2-666 804

R. KLKN

CRMC CNRS Campus L Iuminy, Case 413

F-1328x Marseille Cedex 9. France

Telefax: + 33-91-418916

\begin{abstract}
A. BARONNET (Industrial, Biological and Molectulur Constals!

CRMC: CNRS. Campus Luminy, Case ylz

F-1328x Marseille Cedex 9 . France

Telefix: + 33-41-418916
\end{abstract}

K.W. BENZ (Micrograrity. Electronic Materials Kristallographisches Inst., Universitä Hebelstr. 25. D-741144 Freiburg. Germany Telefax: + $49.761 \cdot 2034369$

A.A. (HERNOV (Kinetics of (nstallization) Inst. Crysiallography. Acad. of Sciences I.eninskii Prosp.. Moscow 1173,33, Russian Fed. Telefax: + 7-095-1,351011

A.Y, (HO) (Molecular Beam Epiaxy) Room IC-323. AT\& T Bell Liboratories Room IC-323. AT\& T Bell Labora
Murray Hill, NJ $179974-2070$, USA Telefax: + 1.41) 5822043

B. COCKAYNE (IOCG News) DRA Malvern, St. Andrews Road. Great Malvern. Worcs. WR 14 3PS. UK Telefax: + 44-1684-894541)

\section{S.R. CORIELL (Theon)}

Als3 Materials

Nati lnst. of Standards \& Technol

Gaithersburgh, MD 20 (1899.(O)O)I, USA

D. EIWELL. (Priority Communications, Superconductic ify'

Hughes Aircraft Company

P.O Box H. M S A2408, 5(M) Superior Avenue

New Purt Beach, CA $42658-8908$, USA

New Purt Beach, CA 42658

ME. GLLCKSMAN (Solidification)

School of Engineering. Mater. Eng. Dept

Rensselaer Polytechnic Inst.

Troy. NY 121(0)-359), USA

Telefax: + 1-518-276 8854

MA.G. HALLJWELL ( $X$-ray Diffraction

Philips Analytical $X$-ray, Lelyweg

7tol 2 EA Almelo, Netherlands

\section{R.S. FEIGELSON}

(Ir. Materials Res., 105 McCultough Bldg.

Stanford Univ., Stanford, ( A Y4305.4(145, IISA

Telefax: + 1.415-723.31)44

T. NISHINAGA

Dep1. Electronic Engineering. University of Tokyo 7-3-1, Hongo, Bunkyo-ku, Tokyo 113, Japan

Telefax: + 81-3-5644-3974

\section{ASSOCIATE EDITORS}

T. HIBIYA (Oxides, Melt Thermophysical

Properties, Micrograitity)

Fundamental Research 1 .ahs.

NEC CORPORATION

34, Miyukigaoka, Tsukuba 305, Japan

Telefax: $+81-298.566136$

H. KOMATSU (Proteins Molectular Crystallization Growth from Solutions)

Inst. Materials Research, Tohoku Univ.

Inst. Materials Research, Tohoku
Katahira 2-1-1, Sendai 980 , Japan

Telefax: + 81-22-2152011

T.F. KUECH (Thin Films and Electromi

and Oprical Derices

Dept. Chemical Engineering

Univ. Wisconsin.Madison

Madion WI 537106, USA

Madison, WI S3nth. USA

A MCPHERSON (Prosein (irowith)

Dept. Biochemistry, Univ. of California

Riverside, CA 92521, USA

Telefax: + (-9099-787 3791)

P.A. MORRIS HOTSENPILILR (Electrempical Crysals, Book Retiews)

E.I. Ju Pont de Nemours \& Co., Exp. Station

Wilmington, DE $19888-10358$, USA

Telefax: + 1-31)2-695 3375

J.B. MUI.LIN (Semiconductors)

EMC. "The Hoo", Brockhill Road

West Matvern, Wores. WR 14 4DL, UK

Telefax: + 44-1684-575 591

K. NAKAJIMA (Liquid and Vapor Phase Epiraxy)

UiSI Mater Iab Fujitsu Labs. IId

ULSI Mater. Lab., Fujitsu

Morinosato-Wakamiy

Atsugi 243-(01, Japan
Telefax: $+81-462.483473$

H. OHNO (Epiaxy)

Research Inst. of Electrical Communication

Tohoku Univ., Sendai 980 77. Japan

Telefax: $+81-22-2175553$

K. PLOOG (Molecular Beam Epitaxy)

Paul-Drude-Inst. für Festkörperelekıronik

Hausvogteiplatz 5-7, D-10117 Berlin. Germany

Telefax: + 49-30-20)3 77201
D.T.J. HURL.E

H.H. Wills Physics Laboratory

Univ. Bristol, Tyndall Avenue

Bristol BS\& ITL. UK

G.B. STRINGFELI.OW

Dept. Materials Science, $3(14$ EMRO

University of Utah

Saht like City, UT 84112, USA

Telefax: + 1-801-5814816

F. ROSENBERGER (Protein Crystallization, Fluid Dynamics)

Center for Microgravity and Materials Research

Univ. Alabama, Huntsville, Al. 35899 , USA

Telefax: + 1-205-895 6791

R.W. ROUSSEAU (Solution Growth,

Industrial ('nytallization)

School of Chemical Engineering

Georgia Institute of Technology

Atlanta, GA 30332-0100, USA

Telefax: $+1.4(14-8942866$

K. SATO (Biocrystallization and

Onganic (rystals)

Fac. Applied Biological Science

Hiroshima Univ.

Higashi-Hiroshima 724, Japan

Telefax: + 81-824-227 062

1.F. SCHNEEMEYER (Superconducri ity.

Oxides, Notel Materials)

Room 1A.363. AT\& T Bell Laboratories

Murray Hill, NJ 07974-2070, USA

Telefax: + 1-908-582 2521

D.W. SHAW (Semiconductors, Epilaxy, Deices) Texas Instruments Inc. P.O. Box 655936. MS 147 Dallas, TX 75265, USA

Telefax: + 1-214-9955539

1. SUNAGAWA (Morphology and Minerals)

3-54-2 Kashiwa-cho. Tachikawa-shi

Tokyo (9), Japan

Telefax: + 81-425-35 3637

G. VAN TENDELOO (Electron Micruscopy.

Fullerenes, Superconductitity)

University of Antwerp, RUCA

Groenenborgerlaan 171

B-20120 Antwerp. Belgium

Telefax: $+32-3-2180217$

A.F. WITT (Semiconductor Cnsials)

Dept. of Metallurgy \& Marerials Science

Massachusetts Institute of Technology

Cambridge, MA 02139 , USA

Telefax: + 1-617-253 5827

A. ZANGWILL (Theron (Epiraxy))

School of Physics. Georgja Inst. of Technol.

Atlanta, GA 303,32 , USA

Telefax: + 1-404-853 4558

Technical Editor: A Kuch, Elsevier/North-Hulland. P.O. Box 2759, J(KM) CT Amsterdam, Netherlands,

Telefax: + 31-20)-48.5 2319, E-mail: koch(') elsevier.nl

Elsevict Science B.V.: All rights reserved. No part of this publication may be reproduced, slored in a retrieval system or transmitted in any form or by any means elecirnic mechanical, photocopying. recording or utherwise, without the written permission of the publisher. Elsevier Science B.V., P.O. Box 103 . I600 AC Amsterdam. Netherlands.

Special regulations for authors - Upon acceplance of an article hy the journal. the author(s) will be asked to transfer copyright of the article to the publisher. This Special regulations for athors - Upon acceplance of an afiche hy the jout

transfer will ensure the widest pussible dissemination of information. Special regulations for readers in the USA - This journal has been registered with the Copyrighi Cleatance Center. Inc. Consent is given for copying of articles for personal or internal use, or for the personal use of specific clients. This consent is given on the condition that the copie pays through the Center the per-copy fee stated in the code on the first page of each article for copying beyond that permitted by Sections 107 or 108 of the US Copyright Law. The appropriate fee should be forwarded with a copy of the first page of the article to the Conyright Clearance Center. Inc., 222 Rosewoud Drive, Danvers, MA 01923, USA. 1f no code first page of an article in this issue will apply retroactively to all articles published in the journal, regardless of the year of publication. This consent does not extend to other kinds of copying, such as for general distrihution, resale, advertising and promotion purposes, or for creating new collective works. Special written permission must be obtained from the publisher for such copying.

permisson must be obtained from the publisher for such copying. No responsihitity is assumed hy the Publisher for any injury and or damage co pertined in the material herein. Although all advertising material is expected to confurm to ethical standards, inclusion in this puhlication does not constitute a guarantec or endursement of the quality or value of such product or of the claims made of it hy its manufacturer.

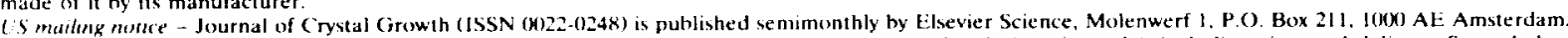
Netherlands. Annual subscription price in the USA is US $\$ 6535$ (valid in North. (entral and South America only). including air speed delivery. Secund class puslage paid at Jamaica NY 11431.

LYA POSTMASTERS. Send address changes to Joumal of (Cystal Growth. Publications Expediting. Inc, 2(n) Meacham Avenue, Elmont NY 1](x)?. Airfreight and mailing in the USA by Publications Lxpediting. 


\title{
Effects of purification on the crystallization of lysozyme
}

\author{
Felecia L. Ewing ${ }^{a}$, Elizabeth L. Forsythe ${ }^{a}$, Mark van der Woerd ${ }^{b}$, \\ Marc L. Pusey ${ }^{c, *}$ \\ ${ }^{2}$ Universities Space Research Association, 4950 Corporate Drive, Suite 100, Huntsville. Alabama 35812, USA \\ ${ }^{\mathrm{U}}$ University of Alabama, Birmingham, Alabama 35294, USA \\ ${ }^{c}$ Biophysics ES76, National Aeronautics and Space Administration, Marshall Space Flight Center, Huntsville, Alabama 35812, USA
}

Received 1 February 1995; accepted 2 September 1995

\begin{abstract}
We have additionally purified a commercial lysozyme preparation by cation exchange chromatography, followed by recrystallization. This material is $99.96 \%$ pure with respect to macromolecular impurities. At basic pH, the purified lysozyme gave only tetragonal crystals at $20^{\circ} \mathrm{C}$. Protein used directly from the bottle, prepared by dialysis against distilled water, or which did not bind to the cation exchange column had considerably altered crystallization behavior. Lysozyme which did not bind to the cation exchange column was subsequently purified by size exclusion chromatography. This material gave predominately bundles of rod-shaped crystals with some small tetragonal crystals at lower pHs. The origin of the bundled rod habit was postulated to be a thermally dependent tetragonal $\leftrightarrow$ orthorhombic change in the protein structure. This was subsequently ruled out on the basis of crystallization behavior and growth rate experiments. This suggests that heterogeneous forms of lysozyme may be responsible. These results demonstrate three classes of impurities: (1) small molecules, which may be removed by dialysis; (2) macromolecules, which are removable by chromatographic techniques; and (3) heterogeneous forms of the protein, which can be removed in this case by cation exchange chromatography. Of these, heterogeneous forms of the lysozyme apparently have the greatest affect on its crystallization behavior.
\end{abstract}

\section{Introduction}

The effects of impurities on the protein crystal growth process has attracted increasing attention [19]. It is now recognized that commercially available lysozyme is not pure, typically containing several macromolecular contaminants as well as assorted buffer and precipitant salts which together often comprise up to $15 \%$ of the dry weight $[5,6,10]$. It is also evident that simple recrystallization does not result in a markedly more pure protein; commercial lysozyme preparations are typically recrystallized

\footnotetext{
* Corresponding author.
}

from 3 to 6 times, yet still contain significant amounts of macromolecular impurities. Sources of the impurities may be from the added solution components or as a result of the preparation process. Alternatively, for many proteins, the growth affecting impurity may be an altered form of the protein itself. For example, proteases are often subject to auto degradation [8]. While the enzymatic function of lysozyme is the lysis of bacterial cell walls, its crystallization behavior can be affected by contaminating fungi [6].

Abergel et al. demonstrated that controlled contamination of turkey with other avian lysozymes affected the nucleation rate and crystal habit, with detectable cocrystallization [4]. Lorber et al. [5], 
using electrophoretic and chromatographic methods, found impurities of $M_{\mathrm{r}} \approx 26,45$, and $80 \mathrm{~K}$ in various commercial lysozyme preparations. They also performed controlled contamination experiments and were able to correlate the amount of contaminating protein added to increased twinning. Wilson, using a differential dialysis system, was able to show the presence of five proteins in a commercial lysozyme preparation, having molecular weights of 14.6 (lysozyme), 17.5, 27.8, 46.8 and $77.9 \mathrm{~K}$ [10]. These molecular weights were maintained in the presence of disulfide reducing agents and a denaturing agent, indicating that all were single chain proteins and not aggregated lysozyme.

Impurities have been implicated in affecting the lysozyme crystal growth process. Lorber et al. indicated a correlation between the impurity level and the solubility, aggregation, and nucleation rate of tetragonal lysozyme [5]. Studies using Michelson interferometry suggested a significant impurity effect on the (101) face growth rate with the presence of a pronounced dead zone [7]. However, averaged face growth rate measurements, using chromatographically repurified protein, were found to be virtually identical to those obtained previously using material prepared by dialysis and recrystallization only $[11,12]$.

Protein molecules are not rigid structures and another form of impurity could be protein which is in a different structural conformation. The evidence suggests that the thermally induced tetragonal $\rightarrow$ orthorhombic transition for lysozyme is based upon a conformational change in the protein structure, and that the orthorhombic form is somewhat stable in the tetragonal phase region $[13,14]$. Structural shifts may also occur in proteins as a response to, for example, the solution $\mathrm{pH}$, ionic strength, or binding to specific molecules in the solution. As in the case of the tetragonal $\leftrightarrow$ orthorhombic shifts for lysozyme, these may be more rapid in one direction than the other, leading to mixed structural populations in apparently homogenous solutions. Thus, one must take the history of the protein into account when assessing purity. The most common method of purity assessment, gel electrophoresis of the reduced and denatured protein, relies on converting the protein into a random coil so that the electrophoretic mobility is only a function of the mass. In such a case, subtle structural changes which may be significant in terms of bioactivity or crystal growth are lost.

For the past several years, this laboratory has used only lysozyme which we have additionally purified by ion exchange chromatography for our growth rate experiments $[11,12,15]$. The initial impetus for the following work came from a reported $0.01 \mathrm{pH}$ unit dependent change in the crystal habit for bovine pancreatic trypsin inhibitor [16]. A temperature, salt concentration, and $\mathrm{pH}$ dependent transition for lysozyme at acidic conditions has been shown on the basis of solubility studies [17]. We believed that a similar effect, with a tetragonal $\rightarrow$ orthorhombic transition, might be found above $\mathrm{pH}=7.0$ based upon reports of the orthorhombic form occurring there when the protein is crystallized from egg white [14,18-22]. The appearance of well-formed tetragonal crystals instead, using highly purified lysozyme, throughout the range investigated $(\mathrm{pH}=7.0-8.9$ ) prompted the following study of the impurities in a commercial lysozyme preparation and the effects of their removal on crystallization behavior.

\section{Materials and methods}

Chicken egg white lysozyme from Sigma (St. Louis, MO, USA, grades I and III) was used throughout this work. Lysozyme concentrations were determined by UV absorbance, using an $A_{(281.5 \mathrm{~nm})}^{1 \%}=$ 26.4 [23]. Measurements of lysozyme catalytic activity were performed using the micrococcus lysodeikticus lysis assay [24].

The lysozyme was repurified by cation exchange chromatography as previously described [11], except that CM-Sepharose 6B-CL (Pharmacia) was used as the exchanger. Briefly, the protein was dissolved in and dialyzed against $0.1 \mathrm{M}$ sodium phosphate, $0.5 \%$ ( $w / v)$ sodium chloride, $\mathrm{pH}=6.4$, at room temperature. The dialyzed protein was clarified by centrifugation, then loaded onto a CM-Sepharose 6B-CL column $\left(2.5 \times 21 \mathrm{~cm}^{2}\right)$ equilibrated with the above buffer. The column was washed with equilibrating buffer and then eluted stepwise with $0.1 \mathrm{M}$ sodium phosphate, $2.87 \%$ sodium chloride, $\mathrm{pH}=6.4$. The column flow rate of $\sim 4 \mathrm{ml} / \mathrm{min}$ was maintained by a peristaltic pump. The eluted protein solution was brought to $10 \%$ sodium chloride by the slow addi- 
tion, with stirring, of the solid salt, then cooled to $4^{\circ} \mathrm{C}$ to promote crystallization. The crystalline suspension was stored at $4^{\circ} \mathrm{C}$ until use, at which time the crystals were recovered by centrifugation, then dissolved in and dialyzed against the buffer to be used in subsequent experiments.

Size exclusion chromatography was performed with a Pharmacia FPLC system and a Superose 12 column at room temperature. The column was equilibrated in $0.2 \mathrm{M}$ ammonium carbonate buffer. The flow rate was $0.5 \mathrm{ml} / \mathrm{min}$ and fractions of $0.2 \mathrm{ml}$ were collected. Protein was prepared for chromatography by dilution into the column buffer to a final concentration of $\sim 1-5 \mathrm{mg} / \mathrm{ml}$. The identity of the ovotransferrin and ovalbumin peaks was verified by running pure samples of both proteins (Sigma) through the column using the same conditions employed for lysozyme. Molecular weights of the impurities were further verified by SDS gel electrophoresis using a PhastSystem gel electrophoresis apparatus (Pharmacia), operated in accordance with the manufacturers instructions and using their low molecular weight standards calibration kit.

Crystallization experiments were set up using a Robotic Protein Crystallization System II (ICN Biomedicals, Inc., Costa Mesa, CA, USA) and CrysChem sitting drop crystallization plates (Charles Supper Co., Natick, MA, USA). Unless otherwise indicated, the final protein concentrations were 30 $\mathrm{mg} / \mathrm{ml}$, and the equilibration conditions for all crystallization solutions were $0.1 \mathrm{M}$ tris buffer (Sigma), $5 \%(\mathrm{w} / \mathrm{v}) \mathrm{NaCl}$ (Sigma, analytical grade), with the $\mathrm{pH}$ ranging from 7.0 to 8.9 in $0.1 \mathrm{pH}$ unit increments. The plates were sealed with clear tape and incubated at $20 \pm 0.5^{\circ} \mathrm{C}$. Crystal face growth rate measurements were performed using the techniques and instrumentation previously described $[25,26]$.

$\mathrm{X}$-ray crystallographic analysis of lysozyme crystals was performed using a Siemens multiwire area detector mounted on a Rigaku rotating anode X-ray generator. $\mathrm{CuK} \alpha$ radiation was generated at $40 \mathrm{kV}$ and $100 \mathrm{~mA}$, and collimated with a graphite monochromator to $0.3 \mathrm{~mm}$. Data was collected at a crystal to detector distance of $12 \mathrm{~cm}$, with the detector $-22^{\circ}$. The oscillation angle during data collection was $0.25^{\circ}$ and each frame of data collected over $60 \mathrm{~s}$. Data was reduced to structure factors with the Xengen package [27].

\section{Results}

The purity of the protein prepared by cation exchange chromatography was assessed with size exclusion chromatography. Previous electrophoretic analysis had indicated that the material was pure, with no other macromolecular contaminants detectable [11]. Size exclusion chromatography was employed to better quantitate any macromolecular impurities remaining. The column elution profiles at two detector scale ranges are shown in Fig. 1. Identical amounts of protein were injected onto the column in both runs. In the first profile, with the detector set at 2.0 absorbance units full scale, the purified lysozyme solution gave a single, fairly symmetrical peak. The slight tailing observed was due to lysozyme binding to the column, a common problem for lysozyme chromatography on carbohydrate matrixbased column media. This problem could be reduced somewhat by the use of higher ionic strength buffers. However, a balance must be observed between the buffer concentration and the protein concentration. Too high a buffer concentration would result in protein crystallization on the column bed. Initial attempts at sample preparation by the dialysis of concentrated protein solution into the $0.2 \mathrm{M}$ ammo-

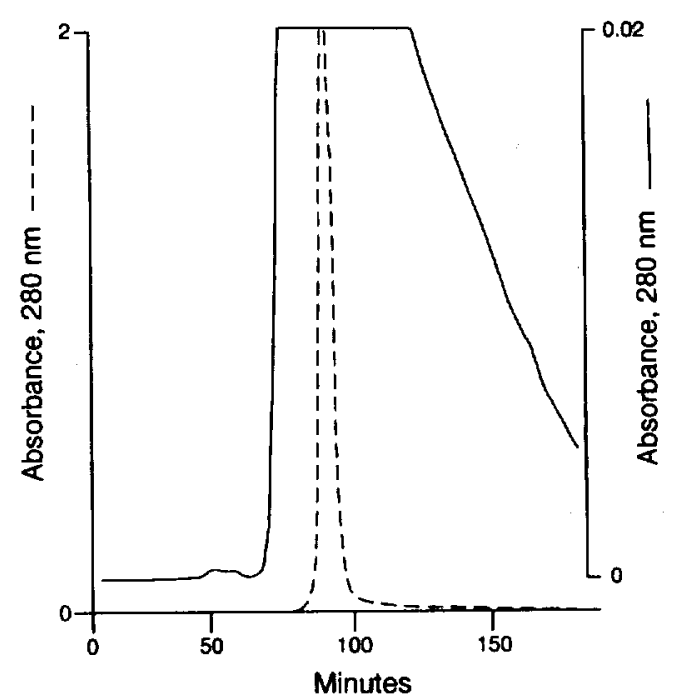

Fig. 1. Gel filtration chromatography of lysozyme prepared by cation exchange chromatography. Two separate chromatographic runs are shown, differing only by the absorbance scale of the UV detector. 
nium carbonate buffer resulted in showers of needle-shaped crystals.

A second profile, with the identical amount of protein loaded onto the column, but the detector set to 0.02 absorbance units full scale, displayed an almost flat base line until the onset of the lysozyme peak. The slight double peak ( $\leq 0.0004$ absorbance units) immediately before the lysozyme peak was residual contaminating proteins. These contaminants have previously been identified as ovotransferrin and ovalbumin $\left(M_{\mathrm{r}}=80\right.$ and $\left.45 \mathrm{~K}\right)$ [5]. We further verified the correspondence of the contaminant peaks with these proteins by separate control runs with pure solutions of each protein. The ratio of the areas of the purified lysozyme peak at the 2.0 absorbance scale and the contaminants peak at the 0.02 absorbance scale was estimated by cutting out and weighing each peak. The slight double peak was divided at the lowest point between the maxima, and the corresponding areas of each part adjusted for the absorbance ratios of ovotransferrin or ovalbumin. On the basis of the adjusted area ratios the chromatographically repurified lysozyme was estimated to be $\geq 99.93 \%$ pure with respect to detectable macromolecular contaminants. Trace amounts of a third contaminant, the serine protease inhibitor ovomucoid $\left(M_{\mathrm{r}} \approx 28 \mathrm{~K}\right)$ [28] cannot be estimated as the peak would be overwhelmed by the closely eluting lysozyme peak. However, ovomucoid binds less tightly to cation exchange columns than ovotransferrin or ovalbumin [29] and therefore it is unlikely that its residual concentration in the purified lysozyme would be greater than that of those two proteins. These results do not rule out the presence of other contaminants which do not absorb at $280 \mathrm{~nm}$. However, the presence of such contaminants, assuming they are protein, has not been observed on SDS gels $[5,10,17]$.

Fig. 2 shows the size exclusion column elution profile from the protein fraction which did not adsorb to the cation exchange column. This material contained the contaminating proteins present in the original lysozyme. In this particular case, most of the lysozyme bound to the column which resulted in the amount of contaminating proteins being greater relative to the amount of non-binding lysozyme. The four peaks, from left to right, are identified on the basis of their molecular weights as ovotransferrin
$\left(M_{\mathrm{r}} \approx 80 \mathrm{~K}\right)$, ovalbumin $\left(M_{\mathrm{r}} \approx 45 \mathrm{~K}\right)$, ovomucoid $\left(M_{\mathrm{r}} \approx 28 \mathrm{~K}\right)$, and lysozyme $\left(M_{\mathrm{r}} \approx 14 \mathrm{~K}\right)$. The slight double peak found on the 0.02 absorbance units scale of Fig. 1 corresponds to the ovotransferrin and ovalbumin peaks of Fig. 2.

A series of crystallization trials, at $0.2 \mathrm{pH}$ unit increments, over the $\mathrm{pH}$ range $7.0-8.9$ were performed on the cation exchange purified lysozyme, the commercial protein, and fractions derived from it. These results are summarized in Fig. 3. The initial observation, that for purified lysozyme only tetragonal crystals were obtained from $\mathrm{pH}=7.0$ through 8.9 , are shown in row (1). Columns (a)-(d) are the crystals obtained at $\mathrm{pH}=7.4,7.8,8.2$, and 8.6 , respectively. A progressive increase in the size and reduction in the number of the crystals was observed as the $\mathrm{pH}$ of the crystallization solution increased. The crystals at higher $\mathrm{pH}$ values, as shown in panel (1d), were flattened along the four-fold axis, characteristic of tetragonal lysozyme grown at high supersaturations [30]. Crystals grown at lower pHs were more elongated along the four-fold axis, indicative of growth at lower supersaturations. The same results shown in row (1) were also obtained when the crystallization buffers were $0.05 \mathrm{M}$ sodium phosphate

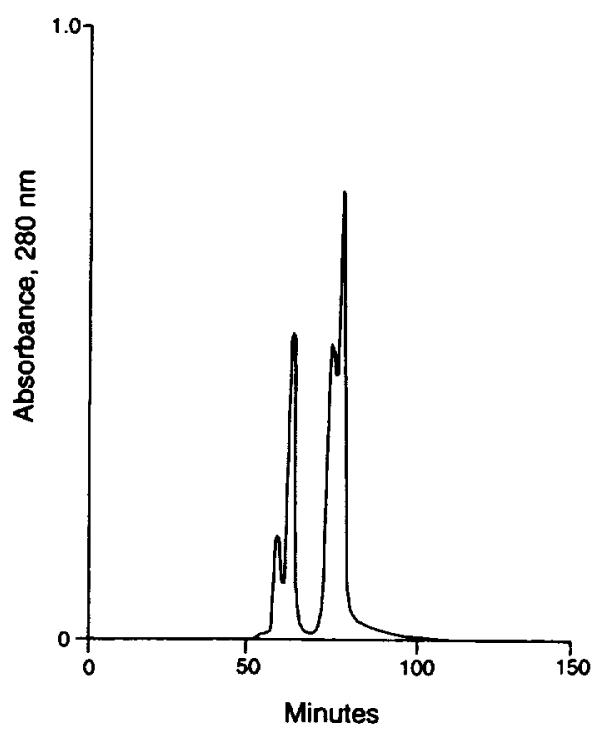

Fig. 2. Gel filtration chromatography of the material which did not adsorb to the cation exchange column. From left to right the peaks are ovotransferrin, ovalbumin, ovomucoid, and lysozyme. 
$\mathrm{pH}=5.7-8.0$ and $0.1 \mathrm{M}$ sodium bicarbonate buffer $\mathrm{pH}=9.2-9.8$.

$\mathrm{X}$-ray crystallographic analysis of the tetragonal crystals grown at $\mathrm{pH}=8.2$ indicated a space group of $\mathrm{P}_{3} 2,2$ with unit cell parameters of $a=b=79.1$ and $c=38.1 \AA$. These results are in close agreement with those found by previous analysis of the tetragonal crystal at acidic $\mathrm{pH}$ [22]. A crystal of dimensions $0.5 \times 0.4 \times 0.4 \mathrm{~mm}^{3}$ was used, yielding 7374 unique (or approximately $90 \%$ of the total possible) reflections at $2.0 \AA$ resolution. The average redundancy was 4.7 , giving an Rsym $=6.9 \%$. A more detailed study is currently underway to identify what structural differences, if any, exist between the acidic and basic crystalline protein structures.

The second row of Fig. 3 shows the crystals obtained with commercial lysozyme prepared by simply dissolving the protein from the bottle into distilled water. A sharp change was found in the crystal habit, occurring between $\mathrm{pH}=7.6$ and 7.8 , with the crystals going from the characteristic tetragonal form to a bundled rod habit. Because of their small size, we were not able to confirm their type by $\mathrm{X}$-ray diffraction. Presumably they are the same as the orthorhombic form previously obtained at basic $\mathrm{pH}$ [14]. The third row of Fig. 3 shows the results obtained when the protein was extensively dialyzed against distilled water prior to crystallization. In this case, only bundled rods were found. As in row (2), the rods appear to become finer with increasing $\mathrm{pH}$.

The procedure for the cation exchange purification of lysozyme used a column equilibration buffer
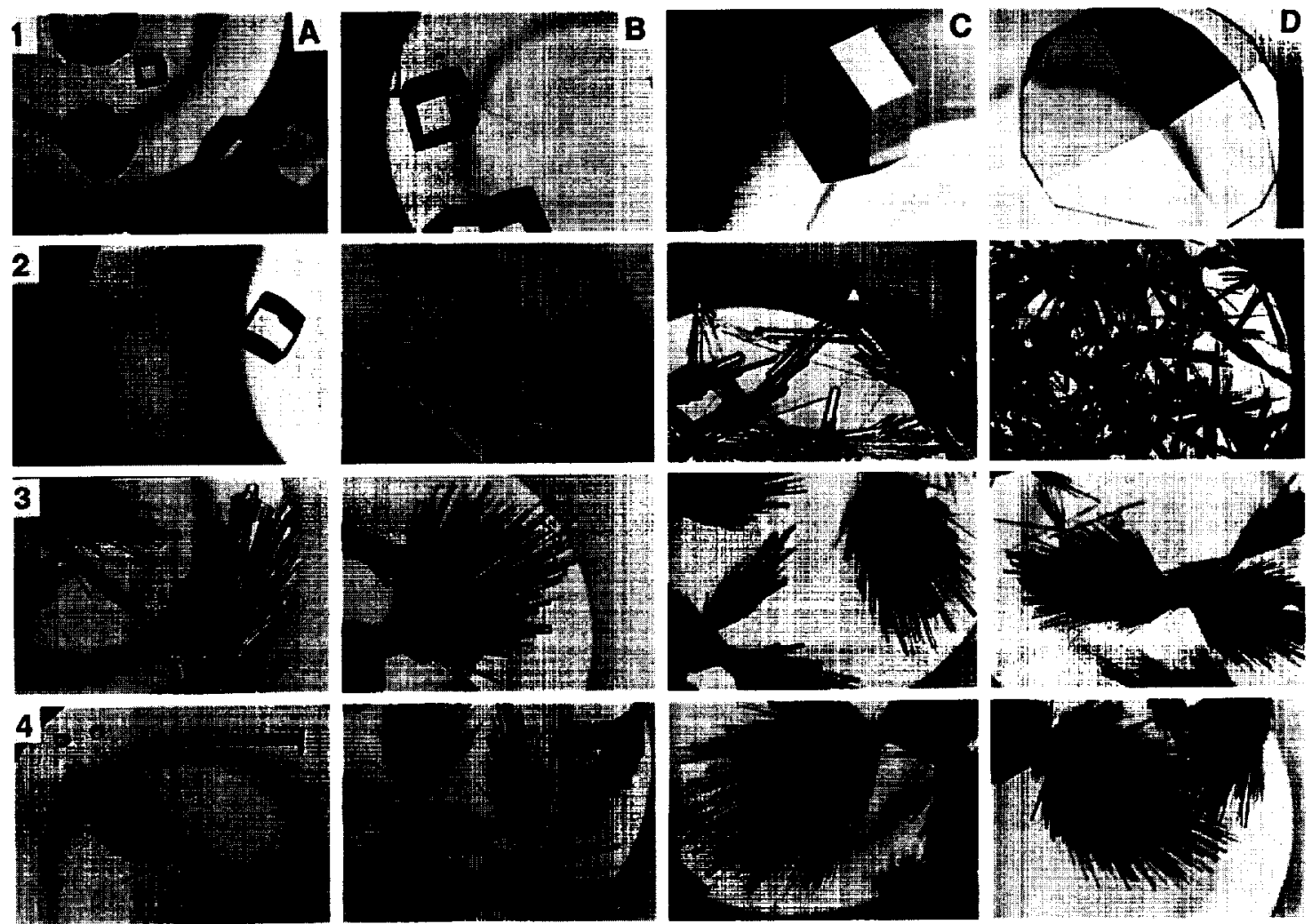

Fig. 3. Summary of the crystallization behavior of the various lysozyme fractions. Each row of photographs is from a different fraction in the purification process, while each column is a different pH. Crystallization pHs are: (a) 7.4, (b) 7.8, (c) 8.2, and (d) 8.6. Row (1) is the cation exchange purified lysozyme, row (2) is unpurified lysozyme used directly from the bottle, row (3) is lysozyme prepared only by dialysis against distilled water, and row (4) is the non-binding protein which was subsequently isolated by gel filtration. All photographs are at the same scale, with the bar in Fig. 4 a equal to $1 \mathrm{~mm}$. 


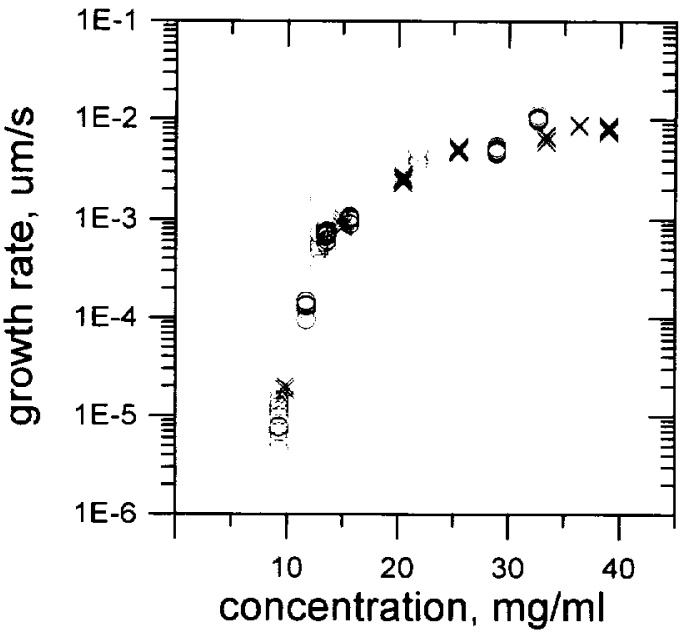

Fig. 4. Effect of the storage temperature on the face growth rate of tetragonal crystals at $20^{\circ} \mathrm{C}$. Legend: $(O)$ protein stored at $4^{\circ} \mathrm{C}$; $(x)$ protein stored at $37^{\circ} \mathrm{C}$.

of $0.1 \mathrm{M}$ sodium phosphate, $0.5 \%$ sodium chloride, $\mathrm{pH}=6.4$. Following loading of the protein onto the column it was briefly washed with equilibrating buffer prior to eluting the bound lysozyme. This procedure often resulted in a large portion of the protein, up to $50 \%$ as determined by UV. absorbance, passing through the column during the loading and washing steps. Electrophoretic analysis had previously shown that some of the non-binding protein was lysozyme, also shown by the size exclusion column elution pattern in Fig. 2. When rechromatography of this material was tried it typically again passed directly through the column. Separate experiments to determine if the non-binding lysozyme was due to overloading of the column indicated that this was not the case. In practice, only $\sim 1 / 5-1 / 4$ of the total lysozyme binding capacity of the column was used for purification runs (data not shown). Purification of the non-binding lysozyme away from the high molecular weight components was accomplished by FPLC on Superose-12. Crystallization of this purified non-binding lysozyme at basic $\mathrm{pH}$ again resulted in crystals of the bundled rod habit as shown in Fig. 3, row (d).

Activity measurements performed with the runthrough, compared to the purified, lysozyme solutions had shown that the catalytic activity/mass of
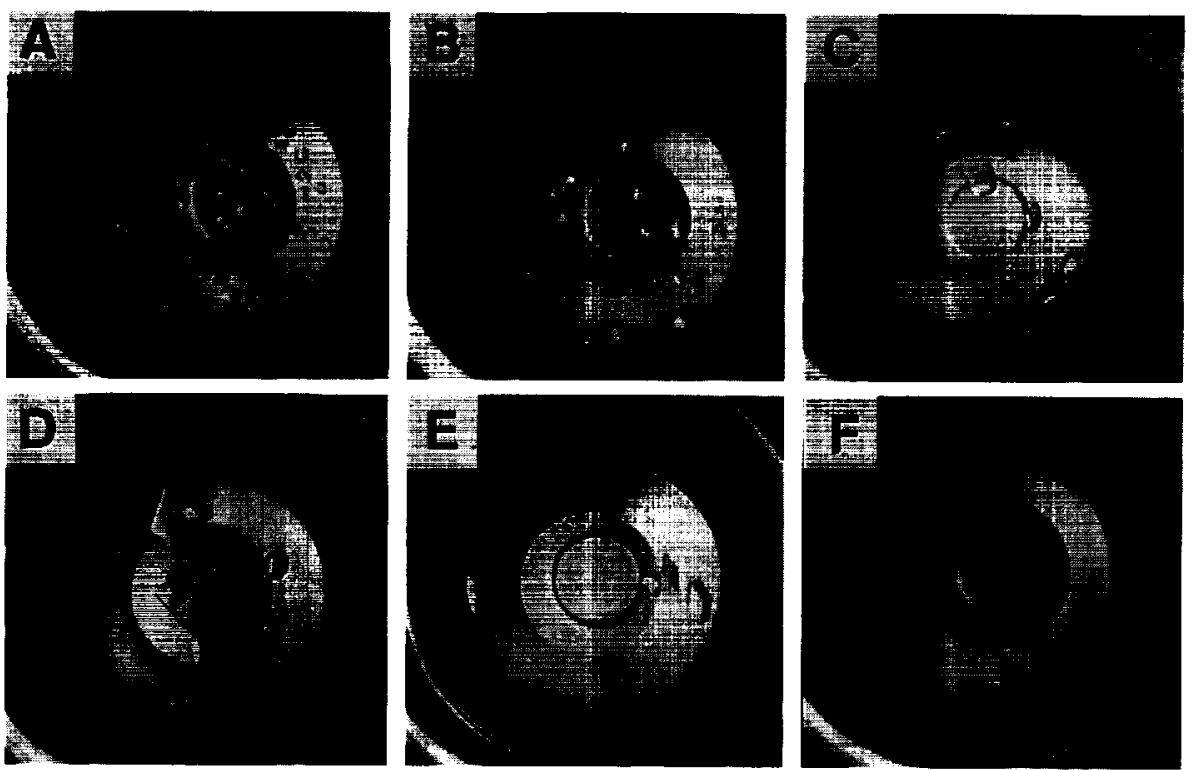

Fig. 5. Effect of storage temperature on the nucleation and growth of crystals at $20^{\circ} \mathrm{C}$. A $30 \mathrm{mg} / \mathrm{ml}$ protein solution was divided in half, with one aliquot stored at 4 and the other at $37^{\circ} \mathrm{C}$. Mixtures were then crystallized by the sitting drop technique. The bar in $(\mathrm{F})$ is $1.0 \mathrm{~mm}$. Legend: (A) $100 \%, 4^{\circ} \mathrm{C}$; (B) $50 / 50,4 / 37^{\circ} \mathrm{C}$; (C) $30 / 70,4 / 37^{\circ} \mathrm{C}$; (D) $20 / 80,4 / 37^{\circ} \mathrm{C}$; (E) $10 / 90,4 / 37^{\circ} \mathrm{C}$; (F) $100 \%, 37^{\circ} \mathrm{C}$. 
protein remained unchanged (data not shown). It was suspected that the origins of the non-binding protein, and thus the altered crystallization behavior, was due to the presence of lysozyme molecules with thermally induced altered conformations. However, warming an aliquot of the protein to $37^{\circ} \mathrm{C}$ for $4 \mathrm{~h}$, followed by fractionation on a small CM Sepharose column with a shallow salt gradient, failed to conclusively demonstrate that this had occurred or, if it had, that the two conformations could be chromatographically resolved (data not shown).

Additional tests were made on whether heat treatment of the purified protein could affect its crystallization behavior. Comparative face growth rate measurements were made at 4 and $20^{\circ} \mathrm{C}$, using protein solutions maintained at 4 and $37^{\circ} \mathrm{C}$. The results for the $20^{\circ} \mathrm{C}$ growth rate measurements are shown in Fig. 4, and indicate that the storage temperature did not affect the growth rates. The results from the growth rate experiments at $4^{\circ} \mathrm{C}$ (data not shown) were comparable to the $20^{\circ} \mathrm{C}$ experiments.

To further test the effects of heat treatment on crystallization behavior, sitting drop experiments were set up to determine the effects on nucleation. As with the growth rate measurements, a lysozyme solution was divided into two aliquots, with one stored at 4 and the other at $37^{\circ} \mathrm{C}$. Sitting drop crystallization experiments were set up at $0.1 \mathrm{M}$ sodium acetate $\mathrm{pH}=4.6$ and $0.1 \mathrm{M}$ tris $\mathrm{HCl} \mathrm{pH}=8.2$, both at $5 \% \mathrm{NaCl}$ and $20^{\circ} \mathrm{C}$, using protein stored at the two temperatures and systematic mixtures of the two solutions. The results were similar at both $\mathrm{pH}$ values, and those for the $\mathrm{pH}=8.2$ experiments are shown in the photographs in Fig. 5. In most of the crystallization wells only tetragonal crystals were obtained, although a few crystals in the bundled rod habit were obtained at $\mathrm{pH}=8.2$. The data indicates that there was a pronounced effect of the storage temperature on the subsequent nucleation rate at $20^{\circ} \mathrm{C}$. A systematic decrease in the number of nuclei formed was found with increasing percentages of the $37^{\circ} \mathrm{C}$ stored protein. However, only a slight increase in size is found with this decrease in nucleation rate, and the axial ratios are similar in all cases. This indicates that all crystals grew at approximately the same supersaturation. For comparison, note the pronounced differences with $\mathrm{pH}$ in the crystals of purified lysozyme in Fig. 3, row (1).

\section{Discussion}

The separation of crystal growth effects due to the presence of impurities versus those due to the solution behavior of the macromolecule itself have become important. A series of publications have recently shown that commercially prepared lysozyme has macromolecular impurities $[5,6,10]$, that added contaminants affect the lysozyme crystallization process $[4,5]$, and that lysozyme crystallization can be affected by microbial contamination [6]. We have also found macromolecular impurities to be present, which determination initially led to the use of cation exchange repurification of commercially available protein [11]. By using this procedure, it is possible to rapidly purify lysozyme in $3-5$ g quantities to $\geq$ $99.9 \%$ purity with respect to other macromolecules. Protein prepared by this procedure has been routinely employed in all growth rate experiments in this laboratory for the last several years $[11,12,15]$. However, previous to the work given above, we had not observed any appreciable difference in the crystallization behavior or growth rate data at acidic $\mathrm{pH}$ when compared to earlier experiments using commercial protein prepared only by recrystallization and dialysis. It was only when we searched for a $\mathrm{pH}$ dependent tetragonal $\rightarrow$ orthorhombic phase change above $\mathrm{pH}=7.0$ that we became aware of an effect which could be linked to the presence of impurities.

During the cation exchange purification process, a considerable fraction of the lysozyme loaded onto the column did not bind, but simply passed on through with the contaminating proteins. Control experiments indicated that the column had not been overloaded. Further, the percentage of non-binding material was not a function of the amount loaded onto the column, but was dependent upon the commercial preparation. Not all commercial lysozyme preparations are equivalent, as previously shown by others $[5,10]$. It has been this laboratories experience that there is variability even with the same material (different lot numbers) from a given vendor. Typically, with the lysozyme (Sigma cat. \#L-7001) most commonly used in this laboratory $\sim 10-50 \%$ does not bind to the cation exchange column. No apparent correlation exists between the amount of lysozyme which binds and the amount of other macromolecular impurities present. This suggests that the lysozyme 
itself was affected by conditions during and after the original purification from the egg white. However, these changes in the crystallization behavior cannot be attributed to a tetragonal $\rightarrow$ orthorhombic conformational shift. Support for this comes from the crystallization behavior of the purified non-binding lysozyme and the purified binding lysozyme, and an inability to conclusively affect the crystal forms obtained at basic $\mathrm{pH}$ by heat treatment. A comparison of the lytic activity of the two protein populations also showed no significant differences. Thus, if there is a change in the protein it does not affect its biological function.

Cation exchange chromatography had been initially used to separate out non-binding lysozyme and other macromolecular impurities. Size exclusion chromatography was then used to separate the nonbinding lysozyme from the other proteins. From a protein purification standpoint, the use of gel filtration is generally not a desirable method for the preparation of large quantities of material. This is especially true for lysozyme. Many of the matrix materials commonly employed for gel filtration resins are based upon carbohydrate backbones, which lysozyme binds. Agarose-based gel filtration media have been employed as an affinity material for the purification of lysozymes [31,32]. Thus, lysozyme tends to either elute at an abnormally low molecular weight (high retention volume) and/or have an elution profile which "tails". This tailing is evident in Fig. 1, despite the use of both high salt and $\mathrm{pH}$ buffer. However, this material had already passed through a cation exchange column without binding. Only a small amount of protein was required for the subsequent crystallization trials, therefore, we resorted to the use of gel filtration chromatography to achieve its purification. A high $\mathrm{pH}$ buffer was used to minimize protein interactions with the column matrix.

The use of cation exchange chromatography for lysozyme purification is not of itself novel. Early reports of lysozyme isolation from egg whites utilized adsorption onto bentonite [18]. The high isoelectric point of lysozyme suggested that weak cation exchangers would be an excellent method for its purification, and after their introduction they have been commonly employed to rapidly isolate lysozyme directly from egg whites [29,33-35]. Most likely, the ready availability of commercial protein preparations that have been purified by multiple recrystallizations has led to the neglect of this simple method of purification.

It is not surprising to find that macromolecular impurities persist even after multiple recrystallizations. The crystalline surface is covered with acidic and basic groups, and has a net charge which will be greater the further from the isoelectric point. Even at the isoelectric point there will be charged groups present. The putative macromolecular impurities also carry a net charge, and may bind to the crystalline surface which acts as an ion exchanger. Rapid nucleation and small terminal crystal size, typical of preparative recrystallizations, result in an increased surface area, all of which means an increased probability of binding other macromolecular impurities which may be present in the solution.

In experiments to test whether exposure to high temperatures $\left(37^{\circ} \mathrm{C}\right)$ may be responsible for the appearance of the bundled rod habit crystals at basic $\mathrm{pH}$, we found that the nucleation process is indeed affected, but that subsequent crystal growth is not. However, no conclusive evidence was obtained that exposure to high temperatures results in the appearance of the (presumably) orthorhombic form at basic $\mathrm{pH}$. The nucleation results differ from those previously obtained by Berthou and Jollès [14]. They found that if the protein solution was preheated at $40^{\circ} \mathrm{C}$, then cooled and crystallization initiated at $20^{\circ} \mathrm{C}$, only orthorhombic crystals were obtained, with an apparent nucleation rate faster than for the corresponding tetragonal crystals from non-warmed solutions. We find instead that the tetragonal form persists despite the warming, and that the nucleation rate is apparently reduced. Berthou and Jollès did find a reduction in the nucleation rate of the tetragonal crystals when the pre-warmed materials were subsequently cooled to $4^{\circ} \mathrm{C}$, similar to our findings at $20^{\circ} \mathrm{C}$. These results suggest that a conformational change is involved. However, if such a change is important to the nucleation of a particular crystal form it is apparently not important for subsequent crystal growth.

These results demonstrate that one cannot rely on a manufacturer's claim of purity by repetitive recrystallization of protein for use in crystal growth studies. Protein crystal growth may be affected by the 
dialyzable (small molecule) and non-dialyzable (macromolecular) components also present in the bottle. However, even after removal of these components, the protein is itself subject to heterogeneity which may have an even greater affect on its crystallization behavior than either other macromolecular or small molecule components. In this study, very little effect is found on the lysozyme crystallization behavior at basic $\mathrm{pH}$ when the macromolecular and small molecule contaminants are removed. The predominate effect may come from heterogeneous forms of the protein itself. We are currently working on isolating these forms, and identifying the alterations responsible for the changes in crystallization behavior.

\section{Acknowledgements}

We would like to thank Laurel Karr for assistance with and use of an FPLC system, and Percy Rhodes and David Donovan for the use of a Zeiss photo microscopy system.

\section{References}

[1] F. Jumak, J. Crystal Growth 76 (1986) 577.

[2] R. Giegé, A.C. Dock, D. Kem, B. Lorber, J.C. Thierry and D. Moras, J. Crystal Growth 76 (1986) 554.

[3] W.F. Anderson, A. Boodhoo and C.D. Mol, J. Crystal Growth $90(1988) 153$

[4] C. Abergel, M.P. Nesa and J.C. Fontecilla-Camps, J. Crystal Growth 110 (1991) 11.

[5] B. Lorber, M. Skouri, J-P. Munch and R. Giegé, J. Crystal Growth 128 (1993) 1203.

[6] N.E. Chayen, J.W. Radcliffe and D.M. Blow, Prot. Sci. 2 (1993) 113.

[7] P.G. Vekilov, M. Ataka and T. Katsura, J. Crystal Growth $130(1993) 317$.
[8] G. Sazaki, S. Aoki, H. Ooshima and J. Kato, J. Crystal Growth 139 (1994) 95.

[9] D.M. Blow, N.E. Chayen, L.F. Lloyd and E. Saridakis, Prot. Sci. 3 (1994) 1638.

[10] L.J. Wilson and F.L. Suddath, J. Crystal Growth 116 (1992) 414.

[11] E. Forsythe, F. Ewing and M.L. Pusey, Acta Cryst. D 50 (1994) 614.

[12] E. Forsythe and M.L. Pusey, J. Crystal Growth 139 (1994) 89.

[13] P. Jollès and J. Berthou, FEBS Lett. 23 (1972) 21.

[14] J. Berthou and J. Jollès, Biochem. Biophys. Acta 336 (1974) 222.

[15] A. Nadarajah, E. Forsythe and M.L. Pusey, J. Crystal Growth 151 (1995) 163.

[16] W.H. Gallagher and K.M. Croker, Prot. Sci. 3 (1994) 1602.

[17] F. Ewing. E. Forsythe and M.L. Pusey. Acta Cryst. D 50 (1994) 424.

[18] G. Alderton and H.L. Fevold, J. Biol. Chem. 164 (1946) I.

[19] J. Berthou and P. Jollès, FEBS Lett. 31 (1973) 189.

[20] K.J. Palmer, Struct. Rep. 11 (1947) 729.

[21] A.V. Elgersma, M. Ataka and T. Katsura, J. Crystal Growth $122(1992) 31$

[22] L.K. Steinrauf, Acta Cryst. 12 (1959) 77.

[23] K.C. Aune and C. Tanford, Biochemistry 8 (1969) 4579.

[24] D. Shugar, Biochem. Biophys. Acta 8 (1952) 302.

[25] M.L. Pusey, Rev. Sci. Instrum. 64 (1993) 3121.

[26] E. Forsythe and M.L. Pusey, J. Crystal Growth 139 (1994) 89.

[27] A.H. Howard, G.L. Gilliland, B.C. Finzel, T.L. Poulos, D.H. Ohlendorf and F.R. Salemme, J. Appl. Cryst. 20 (1987) 383.

[28] J.G. Davis, C.J. Mapes and J.W. Donovan, Biochemistry 10 (1971) 39

[29] R.E. Feeney, J.S. Anderson, P.R. Azari, N. Bennetl and M.B. Rhodes, J. Biol. Chem. 235 (1960) 2307.

[30] S.D. Durbin and G. Feher, J. Crystal Growth 76 (1986) 583.

[31] J.M. Fernández-Sousa and R. Rodriguez, Biochem. Biophys. Res. Commun. 74 (1977) 1426.

[32] J.M. Femández-Sousa, R. Perez-Castells and R. Rodriguez, Biochem. Biophys. Acta 523 (1978) 430.

[33] M.B. Rhodes, P.R. Azari and R.E. Feeney, J. Biol. Chem. 230 (1958) 399.

[34] P. Jollès, H. Zowall, J. Jauregue-Adell and J. Jollès, J. Chrom. 8 (1962) 363.

[35] R.C. Chandan, R.M. Parry and K.M. Shahani, Biochem. Biophys. Acta $110(1965) 389$. 
